\title{
LAÍSMO Y LOÍSMO EN EL LIBRO DE BUEN AMOR
}

M. Jesús López Bobo

Universidad de Ovicedo

\section{INTRODUCCIÓN}

1. Si los estudios sobre las alteraciones en el uso de los pronombres átonos de tercera persona en función Implemento han sido objeto de atención preferente por parte de los estudiosos del pronombre, no es semejante la atención que los gramáticos han prestado al análisis de las desviaciones de estos pronombres en función Complemento'. Quizás, ello se deba a que loísmo y laísmo son fenómenos más tardios, de menor auge, y condenados hace siglos por la normativa académica.

Es común entre los gramáticos atribuir estos dos fenómenos a la tendencia de la lengua a eliminar la distinción causal -que no existe en los demás pronombres - y a reforzar la distinción genérica, existente en todos ellos. El triunfo de esta tendencia hubiera originado un sistema coherente, sin distinción de caso, que constaría de /le, la, lo/ en singular y de /los, las/ en plural. Pero ocurrió que el laísmo no llegó a imponerse ni siquiera en

E., «Das spanische Personal-pronomen", en $Z R P h$, XVII, 1893, pp. 5-7; ME. NÉNDEZ PIDAl, Cantar de Mio Cid. Texto, gramática y vocabulario, volumen I, Madrid 1976; Rufino José CuERvo, «Los casos enclíticos y proclíticos del pronombre de tercera persona en castellano", Romania, XXIV, 1895, pp. 95-113 y 219-263; Francisco MARCos MARIN, Estudios sobre el pronombre, Madrid, Gredos, 1978; Salvador FERNÁNDEZ RAM los origenes y evolución ñola, Madrid, ed. Revista de Occidente, 1951; Rafael LAPESA, «Sobre Tübingen 1968, pp. 523del leísmo, laismo y loismo», en Festschrift Walther wo wañol antiguo", en RFE, LXI, 551; Teresa ECHENIQUE ELIzONDO, «Sistema referencial en español 1981, pp. 113-157. 
zonas laístas; y, por su parte, el uso de /los/ para el masculino plural sufrió la competencia de la trasgresión contraria, esto es, el uso de /les/ para el acusativo $^{2}$.

Como consecuencia de todo esto, ese paradigma nunca llegó a imponerse.

Nuestro propósito es realizar un estudio lingüístico detallado sobre el laísmo y loísmo en el siglo XIV. Hemos seleccionado como objeto de nuestra investigación el Libro de Buen Amor, por su carácter popular, por conservarse en tres manuscritos pertenecientes a zonas geográficas distintas, y por ser ésta la primera obra en que, según los gramáticos, se dan las primeras muestras de laismo. Además, sirve éste para completar toda una serie de trabajos que hemos realizado sobre el uso pronominal en esta obra ${ }^{3}$.

2. Como cuestión previa al análisis de datos, haremos unas reflexiones sobre las ediciones utilizadas, asi como sobre los problemas que plantea este tipo de análisis gramatical. Para el recuento de ejemplos, hemos utilizado la edición crítica de Joan Corominas ${ }^{4}$.

Hemos limitado nuestro trabajo al estudio de los tres manuscritos más completos que se conservan de la obra: $\mathbf{S}$ (o códice de Salamanca, ms. leonés de principios del siglo Xv), T (o códice de Toledo, copiado en el Sureste de León hacia 1380, según nuestras propias conclusiones ${ }^{5}$,) y $\mathbf{G}$ (códice de Gayoso, manuscrito castellano del año 1389). Para el manuscrito $S$, hemos utilizado el facsímil del mismo. Asimismo, hemos completado nuestro trabajo con un análisis del uso pronominal utilizado en la reconstrucción que Corominas hace del original.

Antes de pasar al estudio lingüístico propiamente dicho, veamos qué factores se dan en esta obra que hayan podido condicionar nuestros resultados:

1) En primer lugar, debemos tener en cuenta las importantes lagunas con que cuenta esta obra, fundamentalmente para el manuscrito $\mathrm{T}$. Hemos realizado los porcentajes sobre las formas conservadas en cada manuscrito.

2 Teresa EChenique Elizondo, «El sistema referencial en español antiguo», RFE, LXI, 1981, pp. 115-116.

${ }^{3}$ Véanse nuestros trabajos, Sobre el leismo en el L.B.A. Uso de los pronombres átonos de 3." persona en construcciones latinas con doble acusativo y De nuevo sobre el leismo en el siglo $X I V$, aun inéditos.

« «El Arcipreste de Hita. El libro, el autor, la tierra, la época», en Actas del I Congreso Internacional sobre el Arcipreste de Hita, Barcelona 1973.

s Véanse las conclusiones a nuestro trabajo Sobre el leismo en el Libro de Buen Amor. 
2) Otro factor a tener en cuenta es la apócope. Considerando que /l'/ puede proceder tanto de /le/como de /lo/, es posible encontrar algún loísmo enmascarado bajo forma apocopada.

3) Un problema importante a la hora de delimitar estos fenómenos es 'el terminológico'. Es obvio que una parte importante de este problema radica en la mezcla que habitualmente se hace de criterios sincrónicos y diacrónicos. Si desde una perspectiva sincrónica, los fazes perder el sueño, el comer y el bever es un claro ejemplo de ló́smo y fablarla es un laismo, no estamos seguros de que en el siglo XIV recibieran tal denominación. Por ello, se impone obrar con suma precaución terminológica, y al tratar de los fenómenos que nos ocupan, debemos intentar delimitar con claridad si se trata de una continuación de un uso latino o bien, se trata de un uso desviado, siguiendo una serie de parámetros todos ellos válidos: antigüedad del texto en relación a la fecha de aparición del fenómeno, carácter popular o culto de éste, tipo de lengua (conservadora o innovadora) y dialecto en que fue escrita, ya que todos estos factores inciden, en gran medida, en la preferencia por una u otra forma.

\section{LAÍSMO Y LOISMO}

a) Precisiones terminológicas e historia de los fenómenos

A la hora de definir los fenómenos que nos ocupan, laísmo y loísmo, es necesario obrar con suma cautela, separando las perspectivas sincrónica y diacrónica. Es común en libros, artículos y diccionarios e incluso en gramáticas de sincronía actual, describir los usos pronominales desde una perspectiva diacrónica.

En general, se designa bajo el término de laísmo el uso de /la/, /las/ como objeto indirecto en lugar de los pronombres etimológicos $/ \mathrm{le} /, / \mathrm{les} /$. Uso condenado, hoy es frecuente en el habla popular leonesa y castellana. Es un fenómeno antiguo, que gozó de gran extensión el el Siglo de Oro, y responde a una tendencia distinguidora del género, aún a costa de la distinción casual.

Ha sido siempre más frecuente en singular que en plural, y con referencia a persona antes que a cosa. En cuanto a su expansión geográfica en esta época, nada se sabe; lo más probable, es que su área de expansión no fuera mayor de la que presenta hoy. 
Entendemos por loísmo el empleo de los pronombres átonos /lo/, /los/, etimológicamente complemento directo masculino, para el complemento indirecto masculino. Es un fenómeno bastante antiguo y más abundante en plural que en singular. Presenta algunas muestras en la Edad Media, aumenta durante los siglos XVI y XVII, pero siempre con índices bajos. Prácticamente ha desaparecido durante los siglos XIX y XX, aunque se registran algunos casos, fundamentalmente, en el habla vulgar.

Centrándonos ya en los siglos que nos ocupan, siglos XIV y xV y, basándonos en la opinión autorizada de los estudiosos que se han ocupado del tema, la situación en zona castellana en esta época se caracterizaria por una gran extensión del loísmo plural y lo que es más importante, parece que es en esta época cuando se registran las primeras muestras fidedignas de laísmo.

\section{b) Metodología y criterios para el análisis de datos}

Antes de pasar al análisis de estos dos fenómenos en el Libro de Buen Amor, vamos a exponer los criterios que hemos seguido para determinar la corrección en cuanto al uso pronominal de algunos verbos y construcciones.

Hemos considerado correcto el uso de los pronombres /lo, la, los, las/ con los verbos falagar, servir, fablar. Se trata de verbos cuyo uso pronominal fue transitivo hasta el siglo XIV. En el Libro de Buen Amor, se encuentran las primeras muestras de leísmo con estos verbos.

En cuanto a las construcciones que en latín regían doble acusativo, hemos considerado incorrecto el uso de /lo, la, los, las/ para las oraciones subordinadas completivas y para aquellas construcciones de infinitivo transitivo más implemento; para aquellas construcciones con infinitivo transitivo sin implemento o con infinitivo intransitivo, el Libro de Buen Amor tiene generalizado el uso del pronombre acusativo, uso que consideramos correcto cuando se trata de construcciones causativas o bien en aquellos casos en que el infinitivo no funciona como implemento del verbo principal, sino como atributo del implemento -función desempeñada en este caso por el pronombre- . En aquellos casos en que no concurran estas circunstancias, hemos considerado el uso del pronombre acusativo como laísmo o loísmo. 
c) Análisis de datos

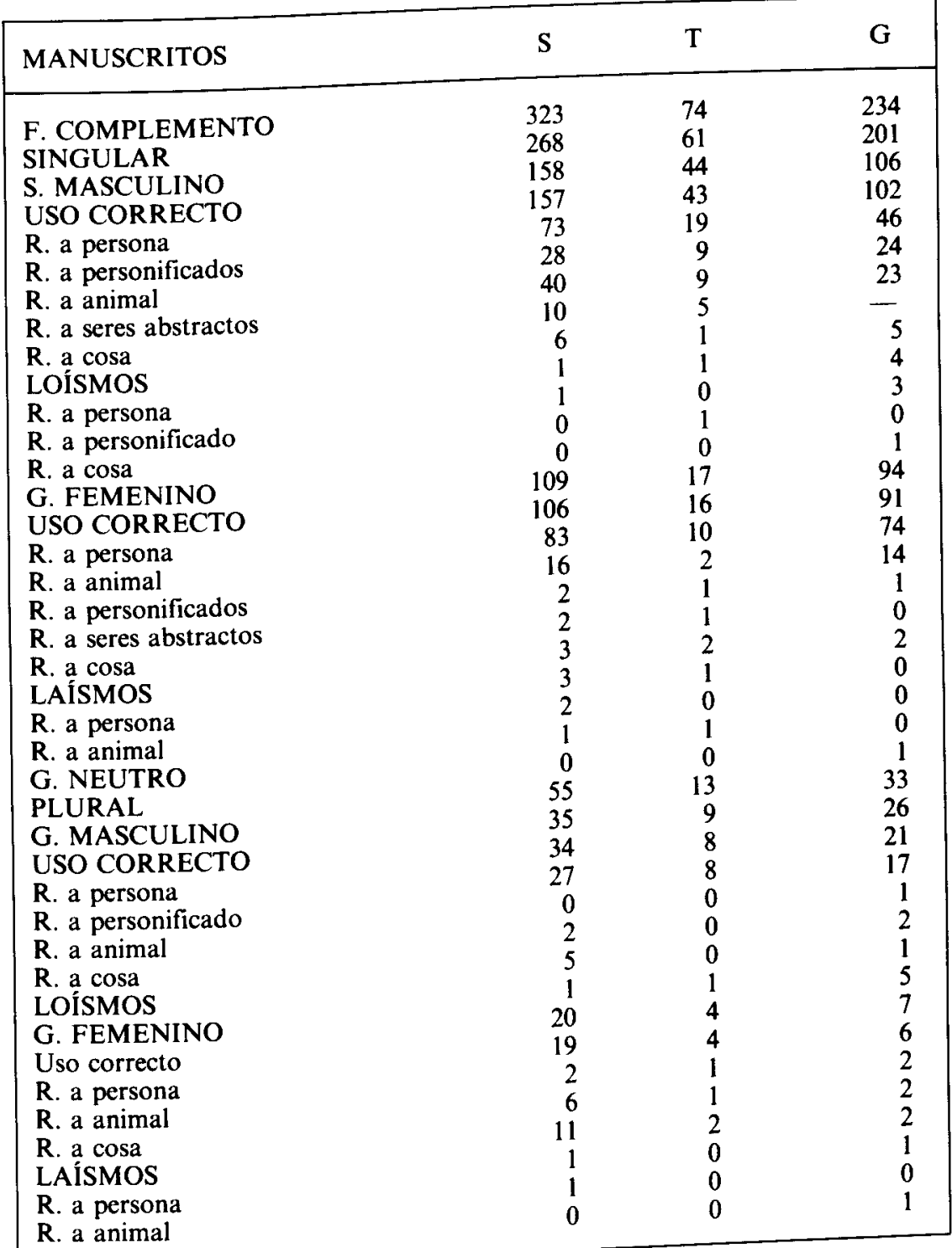


RECONSTRUCCIÓN DE COROMINAS: COR

COMPLEMENTO

SINGULAR

GÉNERO MASCULINO

USO CORRECTO

Referidas a persona

Referidas a personificados

Referidos a animal

Referidos a seres abstractos

Referidos a cosa

LOÍSMOS

Referidos a persona

Referidos a personificados

Referidos a cosa

GÉNERO FEMENINO

USO CORRECTO

R. a persona

R. a personificados

R. a seres abstractos

R. a animal

R. a cosa

LAÎ́SMOS

4

R. a persona

R. a animal

GENERO NEUTRO

PLURAL

GÉNERO MASCULINO

USO CORRECTO

R. a persona

R. a personificados

R. a seres abstractos

R. a animal

R. a cosa

LOÍSMOS

R. a persona

GENERO FEMENINO

USO CORRECTO

R. a persona

R. a animal

R. a cosa

R. a seres abstractos

2

LAISMOS

R. a persona

R. a animal 


\section{1) Loismo}

Ya Rafael Lapesa ${ }^{6}$ y otros, han señalado cómo el uso de /lo, los/ por $/ \mathrm{le}$, les/ es un fenómeno bastante antiguo y mucho más frecuente en plural que en singular; se trata, además, de un fenómeno dificil de escindir - a menos en sus origenes- del uso etimológico ya que se da fundamentalmente en construcciones que, rigiendo acusativo en latín, pasan a construirse en romance con dativo; la circunstanicia de que sean precisamente los textos más conservadores los que presenten más casos de loísmo, dificulta aún más la tarea de su detección.

Veamos cuál es la situación exacta del loísmo en el Libro de Buen Amor.

Un análisis detallado de las cifras que muestran las tablas, arroja la siguiente información:

a) La extensión del loísmo varía de un manuscrito a otro: Asi, en $\mathrm{S}$, el loísmo es escaso, elevándose a un 1 por 100 sobre los usos totales (de 193 formas masculinas en función de complemento, hay dos loísmos y 191 formas correctas). Algo superiores son las cifras en los otros dos manuscritos: en $\mathrm{T}$, de 53 formas masculinas en función de complemento, dos son incorrectas (un 4,5 por 100 sobre los usos totales), mientras que $\mathrm{G}$, es el manuscrito que presenta un porcentaje más alto de lóismos, un 7,5 por 100 , ya que de 132 formas, 124 son correctas y nueve incorrectas. Probablemente, el copista de S, a pesar de ser un hombre eminentemente conservador, era consciente de que el uso de acusativo en determinadas construcciones, aún siendo etimológico, era inusual en la época en que él escribía.

b) En cuanto al porcentaje de usos incorrectos según el antecedente, nuestro estudio no hace sino corroborar el dominio del loísmo para el plural.

Así, en el manuscrito $S$, un 0,6 por 100 de las formas singulares son incorrectas, mientras que las cifras se elevan a un 30 por 100 para el plural; en T, un 2,3 por 100 de las singulares y un 12,5 por 100 de las plurales son incorrectas; otro tanto ocurre en $\mathrm{G}$, donde un 19,2 por 100 de las formas plurales son incorrectos frente a un 3,7 por 100 de las singulares.

Para el original perdido, el porcentaje de usos incorrectos se elevaría - según la reconstrucción que hace Corominas - a un 1 por 100 situándose, pues, más cerca de $\mathrm{S}$ que de $\mathrm{G}$ y $\mathrm{T}$. En este sentido,

- LAPESA, R., Leismo, laismo y loismo..., op. cit., p. 548. 
resulta aceptable la reconstrucción que Corominas hace del original; por otra parte, coincidiendo con los demás manuscritos, presentaría un porcentaje mucho mayor de loísmos plurales que singulares.

Veamos, a continuación, los loísmos encontramos en el Libro de Buen Amor, así como las construcciones que favorecen su aparición.

\section{LOISMOS SINGULARES}

En el Libro de Buen Amor, hemos registrado un total de seis loismos ( 1 en $S, 1$ en $T$ y 4 en $G$ ). Determinar la incorrección que supone el uso del pronombre acusativo en todos estos casos, no plantea ninguna dificultad, pues en todos ellos, el pronombre es complemento del verbo principal, ya porque aparezca en construcciones cuyos verbos son intransitivos, en subordinadas completivas o bien, con verbos que ya cuenten con implemento, circunstancias que imposibilitan al pronombre para funcionar como implemento. Además, se trata de textos demasiado modernos como para calificar tales usos de «etimológicos».

Solamente contamos con un ejemplo que podría ser objeto de una doble interpretación sintáctica:

$$
\text { «al corazón, fázeslo andar volando» (211 a) }
$$

donde aparentemente, lo podría funcionar como complemento del verbo principal («se lo fazes») si bien, nos inclinamos por considerar ésta una construcción atributiva, calificando por tanto el uso del acusativo como correcto?.

Los ejemplos encontrados son los siguientes:

\section{MANUSCRITO S}

- Estr. 53 a: "vistiéronlo muy bien paños de grand valor»

' En nuestro trabajo "Uso pronominal átono en el Libro de Buen Amor para construcciones con doble acusativo latino" se hace un detallado análisis del uso pronominal en estas construcciones. 


\section{MANUSCRITO T}

— Estr. 1303 b: «atrevim preguntarlo que..."

\section{MANUSCRITO G}

- Estr. 953 b: «al que me paga non lo fago enojo»

- Estr. 1051 b: «dándolo Judas paz»

- Estr. $1052 f:$ (a Cristo) "escúpenlo encima»

- Estr. 887 b: (al cuerpo) «el quexamiento non lo puede pro tornar

\section{LOÍSMOS PLURALES}

Para el plural, hemos encontrado un total de siete loísmos (uno en $\mathbf{S}$. uno en $\mathrm{T}$ y cinco en $\mathrm{G}$ ). La incorrección que supone el uso del acusativo en todos estos ejemplos es evidente por aparecer en construcciones cuyos verbos son intransitivos (tres casos en $\mathrm{G}$ y uno en $\mathrm{T}$ ), en oraciones subordinadas completivas (dos casos en $G$ ), o en oraciones con verbo subordinado que lleva implemento (uno en $\mathbf{S}$ ).

En todos estos casos, el pronombre a utilizar ha de ser complemento, y, por lo tanto, el uso del acusativo constituye un loísmo. Además, la preferencia del loísmo a manifestarse en plural nos hace ver más claro aún en este caso la inconveniencia de calificar estos usos como etimológicos.

Los ejemplos encontrados son los siguientes:

\section{MANUSCRITO S}

- Estr. 184 b: (a muchos) «el sueño perder fázeslos, el comer y el bever».

\section{MANUSCRITO T}

- Estr. 1183 c: "pascua de pan los venia».

\section{MANUSCRITO G}

- Estr. 495 a: "Respondiólos la dueña que ella querié casar». 
- Estr. 1158 c: "devédeslos mandar que puedan aver su cura».

- Estr. 498 b: «muchos merecién la muerte que la vida los dava».

— Estr. 1366 c: "el malo a los suyos non los presta un figo».

- Estr. 1183 c: "pascua de pan los venia".

Para el original, Corominas sólo reconstruye un verso en que el uso pronominal sea incorrecto:

- Estr. 184 b: "el sueño perder fázeslos, el comer y el bever».

Ahora bien, junto a este último ejemplo donde no cabe dudar de la incorrección que supone el uso del acusativo tenemos dos versos que presentan construcciones muy similares y para las que la etiqueta de incorrectas' no es adecuada. Corresponde a los siguientes versos:

- Estr. 1565 a: (a los perdidos malos) «los fazes tú arder».

- Estr. 1565 c: (a los perdidos malos) «los fazes encender».

En estos dos ejemplos, el uso del acusativo está plenamente justificado, ya que sintácticamente el pronombre es implemento del verbo principal y, además, desde una perspectiva semántica, estamos ante construcciones transitivas.

\section{2) Laismo}

El uso de /la, las/ en lugar de /le, les/ es una desviación gramatical muy generalizada en el Siglo de Oro y hoy, está condenada por la Academia. Según Lapesa ${ }^{8}$, los primeros ejemplos seguros datan del siglo XIV.

En el Libro de Buen Amor, se da aproximadamente en la misma proporción que el loísmo, sin alcanzar cotas semejantes a las del leísmo.

" Lapesa, R., Leísmo, laismo y loísmo..., op. cit., p. 548. 
Un análisis detallado de las cifras que muestran los cuadros nos arroja los siguientes resultados:

a) La extensión del laísmo varía, como era de esperar, de un manuscrito a otro; así, en el manuscrito $S$, el porcentaje de usos incorrectos para el pronombre femenino en función de complemento es de un 3,1 por 100 (de 129 formas, hay cuatro laísmos, frente a 125 formas correctas). Algo superiores son las cifras en los otros dos manuscritos: en $\mathbf{G}$, el porcentaje de usos incorrectos se eleva a un 4 por 100 ya que de 101 formas, 97 son correctas y cuatro incorrectas. T, por su parte, es el manuscrito que presenta mayor porcentaje de laísmos (un 5 por 100), ya que de 21 formas, uno es incorrecta. En cuanto al original perdido, presentaría - según la reconstrucción que Corominas hace- un porcentaje de usos incorrectos semejante al de $\mathbf{S}$.

Resulta sorprendente que $\mathbf{S}$, manuscrito copiado casi cien años después de que se redactara el original, no presente ningún avance del laísmo con respecto a éste y que sus cifras se mantengan muy por debajo de T y G, copiados bastantes años antes. Por su parte, $G$ y T dan buena cuenta del avance experimentado por el laísmo en los 50 años que median entre la redacción del original y la fecha en que éstos fueron copiados.

b) Desde las primeras investigaciones sobre esta cuestión, los gramáticos han insistido en el predominio del laísmo singular sobre el plural. Sin embargo, nuestro estudio no corrobora esta afirmación. Así, en S, un 2,7 por 100 de las formas singulares son incorrectas frente a un 5 por 100 de las plurales; algo parecido ocurren en $T$ y en $\mathbf{G}$, donde un 5,9 por 100 y un 3,2 por 100 de los usos singulares, respectivamente, son incorrectos, frente a un 14,3 por 100 de los plurales.

Los laísmos encontrados en la obra son los siguientes:

\section{MANUSCRITO S}

SINGULAR

- Estr. 268 b: (a la dueña) «nunca la ovo talante». 
- Estr. 73 b: (al avutarda) «los ballesteros peláronle las alas / non la dexaron dellas sinon chicas e ralas".

- Estr. 643 b: (a tu amiga) "su madre non la consintra fablar».

PLURAL

- Estr. 168 b: (a las dueñas) «las veza».

\section{MANUSCRITO T}

— Estr. 219 d: (a la liebre) «la echa la galga».

\section{MANUSCRITO G}

— Estr. 883 b: "si las aves sopiessen quantos de lazos las paran».

El original presentaría, según la reconstrucción que hace Corominas, los siguientes laísmos:

\section{SINGULAR}

- Estr. 268 b: (a la dueña) "nunca la ovo talante».

- Estr. 385 a: (a la que vien) «Sede a dexteris meis, dizesla a la que vien

— Estr. 396 a: (a la dueña) «dásla mal consejo».

- Estr. 643 b: (a tu amiga) «su madre non la consintra fablar.

\section{PLURAL}

- Estr. $168 d:$ (a las dueñas) "las veza».

Ahora bien, junto a todos estos ejemplos en que es evidente que el uso 
del acusativo supone una desviación gramatical, (ya por tratarse de verbos que cuentan con su propio implemento («talante», «dellas», «la galga», o «fablar») - por lo que el pronombre pasa a ser interpretado como complemento del verbo principal- ya de verbos intransitivos), tampoco aquí nos han faltado ejemplos cuya corrección vimos claramente sólo tras analizar el tipo de construcción en que intervenían. Son los siguientes:

- Estr. 521 c: «la fará estar».

- Estr. $521 d$ : «la fazen saltar».

- Estr. 559 b: «la fazes entristecer».

-- Estr. 387 c: (a las dueñas) "las fazes abaxar».

Cuervo explica el uso del acusativo en estas construcciones como consecuencia de la equivalencia que, a veces, se establecía en la lengua medieval entre verbos transitivos y frases que les correspondian por la significación, formadas por un verbo de sentido general y un acusativo que lo determinaba. Quizás, nuestro copista consideró equivalentes construcciones del tipo «la fará estar» y «la fazen saltar» a verbos transitivos del tipo tranquilizar o exaltar. Por otra parte, desde una perspectiva sincrónica, estas construcciones pueden considerarse atributivas.

\section{CONClusiones}

Si un análisis del uso de los pronombres átonos en función de implemento en el Libro de Buen Amor muestra el gran avance experimentado por el leísmo en el siglo con respecto a épocas anteriores, el análisis de los pronombres átonos utilizados en función de complemento nos lleva a concluir:

a) Que el laísmo y el loísmo no eran fenómenos abundantes en el si-

- Cuervo, Los casos encliticos y procliticos del pronombre..., op. cit., p. 238. 
glo XIV, aunque los ejemplos con que contamos son ya seguros y fácilmente separables del uso etimológico.

b) En cuanto a los porcentajes de aparición de estos dos fenómenos en los distintos manuscritos, los resultados de nuestro escrutinio se muestran en desacuerdo con lo que cabría esperar para cada manuscrito, sobre la base de fechas y lugares en que - según Corominas- fueron copiados. Así,

1) de nuestro estudio, resulta que $S$ es el manuscrito más correcto, con un 3,1 por 100 de laísmos y un 1 por 100 de loísmos. A primera vista, sorprende que el manuscrito más alejado en el tiempo del original, sea a su vez, el más correcto en un período de rápida evolución de la lengua. Sin embargo, un estudio de la personalidad del copista nos aclara mucho los hechos; quizás, los escasos laísmos y loísmos que aparecen en este texto puedan atribuirse a la gran cultura y pose de modernidad de su copista, quien, seguramente, los evitaba por inusuales en la época en que escribia. Por otra parte, la mayor parte de los laísmos y loísmos que aparecen en este manuscrito, corresponden a versos que $\mathbf{G}$ y $\mathbf{T}$ no conservan.

2) T, por su parte, ocuparía el segundo lugar en cuanto a usos incorrectos en función complemento, con un 4,5 por 100 de laísmos y loismos.

G, sería - según nuestro escrutinio-, el manuscrito más incorrecto con un 4 por 100 de laísmos y un 7,5 por 100 de loísmos.

Lo que evidentemente se deduce del análisis de estas cifras es que $\mathbf{G}$ y $\mathbf{T}$ muestran el gran avance experimentado por estos dos fenómenos en los cien años que median entre la redacción del original y la fecha en que éstos fueron copiados.

Ahora bien, si la supuesta fidelidad de sus copistas al original -que tan a menudo se atribuye a $\mathbf{G}$-, puede explicar el hecho de que este manuscrito, procediendo de la misma recensión que T y habiendo sido copiados en fechas semejantes, presente menor número de leísmos que éste, no consideramos igualmente atribuible a esa supuesta fidelidad de $\mathbf{G}$, el mayor número de loísmos que presenta con respecto a $\mathbf{T}$, sino que más bien, parece un fenómeno ligado a la incultura de sus escribas. 
En cuanto al supuesto original, la reconstrucción que Corominas hace de éste muestra unos porcentajes de usos incorrectos semejantes a los de $\mathbf{S}$, cifras que pueden aceptarse dado el espacio de tiempo que media entre el original y G-T. 